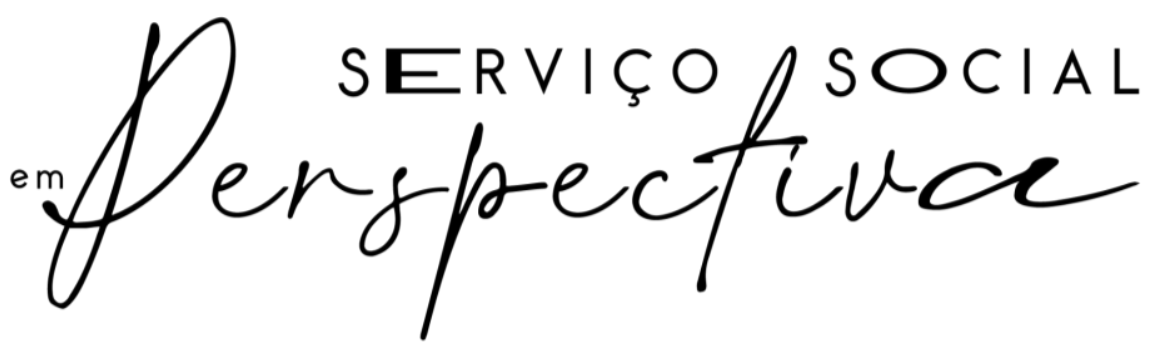

Montes Claros (MG), volume 5, número 1. jan./jun. 2021. I ISSN 2527-1849

\title{
A URGÊNCIA DO DIREITO À CIDADE E AS ALTERNATIVAS DE ENFRENTAMENTO À COVID-19 EM TERRITORIOS VULNERABILIZADOS
}

\author{
THE URGENCY OF THE RIGHT TO THE CITY AND THE ALTERNATIVES TO FACE COVID-19 IN \\ VULNERABLE TERITORIES
}

Giselle Silva Soares ${ }^{1}$

\begin{abstract}
Resumo: $O$ presente artigo tem como objetivo relacionar os reflexos da pandemia da Covid-19 com a condição de vida da população vulnerável do país. Apresenta também uma aproximação entre a noção sobre o direito à cidade e a resposta construída para o enfrentamento da pandemia por moradores de Paraisópolis, na cidade de São Paulo. O direito à cidade. inicialmente debatido por Lefévre pressupõe que o espaço urbano deveria se constituir como espaço público onde toda a população teria o acesso para ampla circulação e utilização desses espaços e serviços disponiveis na cidade. No entanto, sob a lógica capitalista, sabe-se que tal processo não se efetiva, uma vez que as contradições sociais definem formas de circulação. usos e espaços da cidade. A experiência vivida pelo moradores da comunidade de Paraisópolis revela a construção de alternativas à crise pela própria população, as características do território, bem como a possibilidade de construção na cidade urbana de bens comuns, de comunalidades, conforme a noção desenvolvida por Harvey. Além disso, aponta a urgência das demandas sociais que devem ser destaques das ações articuladas do poder público brasileiro. Desta forma, o direito à cidade pode revelar as urgências e as demandas coletivas de grupos vulnerabilizados residentes em diferentes territórios, especialmente de diferentes centros urbanos.
\end{abstract}

Palavras-chave: direito à cidade, território, vulnerabilidade e questão social.

Abstract: The present article has the goal of connecting the Covid-19 pandemic's reflects to the living condition of the country's vulnerable population. It also presents an approximation between the notion about the right to the city and the answer constructed to face the pandemic by the people who live in Paraisópolis, in São Paulo city. The right to the city. firstly debated by Lefévre presupposes that the urban space should constitute a public space where the whole population would have access to wide circulation and use of those spaces and services available in the city. However, under the capitalistic logic, is known that this process doesn't happen, once that the social contradictions define ways of circulation, use and spaces of the city. The experience lived by Paraisópolis community's residents reveals a construction of alternatives to the crisis by the population herself, the territory's features as the possibility of common wellness' construction in the urban city, of commonalities, according to the notion developed by Harvey. Besides that, it points the urgency of social demands that must be highlighted by the articulated actions of the Brazilian government. In this way, the right to the city reveals the collective urgencies and demands of vulnerable groups that live in different territories, especially in different urban centers.

Keywords: right to the city, territory, vulnerability and social question.

\footnotetext{
${ }^{1}$ Cientista Social e Assistente Social. Cientista Social pela FFLCH-USP. Assistente Social pela UNIFRAN. Mestre e Doutora em Serviço Social pela PUC-SP. Professora do Curso de Serviço Social da Unimes - Santos/SP. giselle.silva.soares@gmail.com
}

Artigo submetido em: 18 de outubro de 2020 .

Artigo aceito em: 30 de novembro de 2020 .

p. 51-64 DOI: https://doi.org/10.46551/rssp202103 
INTRODUÇÃO

Sabe-se que a covid-19 intensificou as mazelas da sociedade brasileira, bem como os níveis de desigualdade social, trazendo à tona os problemas latentes em torno da vulnerabilidade social, em diferentes grupos da sociedade brasileira que dependem muitas vezes dos serviços públicos ou do sistema de proteção social.

Nesse quadro, a questão sobre universalização dos direitos preconizados na CF/1988 ganhou destaque nos debates e reflexões sobre o cenário sociopolítico brasileiro, evidenciando processos de enfraquecimento dos direitos sociais e da relevância da existência do sistema de proteção social no país.

Sabe-se que a situação entorno da atual pandemia acometeu o mundo. No entanto, as respostas do Brasil frente ao quadro de contaminação e a dificuldade em combater esse processo de adoecimento escancararam as dificuldades dos governantes do país em realizarem ações articuladas e um plano de enfrentamento da pandemia pautado nos princípio da descentralização político-administrativa.

Contudo, a relação entre pobreza, contaminação e óbito é estreita no país, configurase em desafio quando se soma a questão econômica, com isso, diante da nova situação esboça-se o velho dilema entre o desenvolvimento econômico e o agravamento da questão social.

O trabalho da população mais empobrecida foi duramente atingido, muitas familias tiveram suas rendas diminuidas ou perderam a possibilidade de manterem suas atividades de trabalho, muitas realizadas dentro da informalidade. Ocorreu uma dificuldade em solicitar e obter o auxilio emergencial instituido pelo governo federal, muitos trabalhadores não conseguiram solicitá-lo seja por falta de acesso às tecnologias, seja por falta de informação.

As demandas e a urgência da economia de mercado sobrepuseram-se diante da urgência da vida e das necessidades básicas da população mais vulnerável, pois era necessário garantir o desenvolvimento e os níveis de crescimento econômico. No entanto, o emprego e a empregabilidade não se constituem nesse quadro como urgentes, prevalecendo o aumento do desemprego, do subemprego e a manutenção do processo de acumulação do capital financeiro. Uma caracteristica da sociedade capitalista, a contradição entre capital e trabalho 
que em nosso tempo se apresenta, sobretudo, pelo fortalecimento da especulação na economia como forma de obtenção de acúmulo de capital. A consequência social direta é a diminuição massiva de postos de emprego regulamentado pela legislação trabalhista vigente.

Por outro lado, a situação em relação aos direitos sociais também é agravante, pois as sucessivas reformas e medidas governamentais dos últimos anos denotam a fragilização e enfraquecimento dos direitos sociais. Ao mesmo tempo, o enfrentamento e o controle dos níveis de contaminação da pandemia no país demandam medidas constituidas pelo poder público, o maior exemplo disso é a existência do SUS. Pode-se pensar que a situação do país não está pior em função do papel que realiza o Sistema Único de Saúde dentro da saúde pública brasileira.

No entanto, esse quadro nos faz pensar sobre as caracteristicas de nossa sociedade que neste momento se agravaram em função do desenvolvimento e do fluxo da atual pandemia. $\bigcirc$ que demanda a realização de alguns questionamentos, tais como as questões de saúde pública que são urgentes, as questões sociais o são da mesma forma. Pode-se considerar que a situação revela a estreita ligação entre as duas dimensões, pois a promoção da saúde à população tem uma implicação social.

Outro aspecto relevante é a condição de cidadania que deveria ser suficiente para promover o direito ao isolamento social. Vale lembrar que para tal realização, o Estado teria que exercer sua função de garantidor desse direito e agir de forma presente como um mediador das relações sociais de produção com o objetivo de equacionar o diálogo sobre cuidado, níveis de produção social e bem comum.

Tal prática permitiria inclusive, a intensificação do diálogo sobre a concepção de bem comum e da construção ou preservação de uma sociedade menos excludente, ou seja, diante de uma situação extrema que acometeu a população mundial e brasileira, caberia aos três níveis do governo brasileiro, a realização do debate e o planejamento de um plano de enfrentamento à crise pandêmica com alcance para a questão de saúde pública, social e econômica. 
Sabe-se que em situações de calamidade pública, cabe ao Estado responder de forma presente e intensa às demandas sociais, mas tal situação só poderia acontecer com a articulação e responsabilização das diferentes esferas de poder do país.

Como podemos aproximar a existência da pandemia da Covid-19 com a concepção de que a questão social se intensifica na realidade social brasileira? Além disso, como podemos pensar que a crise sanitária revela aspectos fundantes da crise socioeconômica do Brasil?

Vale lembrar que entre os efeitos da questão social no Brasil estão as diversas formas que intensificam a pobreza da população. Nesse processo se destacam as condições de vida, bem como as condições de trabalho de uma parcela considerável da população. A questão social revela o processo de exclusão da população ao trabalho, aos níveis de escolaridade, às condições de moradia e à própria utilização da cidade.

Há, portanto, uma relação entre questão social e vulnerabilidade que se expressa nos baixos niveis de condição de vida da população, no acesso desse grupo social aos serviços básicos de saúde como destaque para o acesso a água, ao saneamento básico, ao gás para cozinhar, aos serviços públicos de saúde e às atividades escolares remotas realizadas pelas escolas em função da pandemia. Tais aspectos inviabilizaram a realização do isolamento social satisfatório e expõe tal população à contaminação ao vírus. Desta forma, pode-se pensar na relação estreita entre pobreza e contaminação ao coronavírus.

A população mais empobrecida, considerando a condição de moradia e a dificuldade de acesso aos serviços encontra-se mais exposta ao risco da contaminação, considerando que as famílias são mais numerosas, o espaço de moradia reduzido, o que inviabiliza a realização do isolamento social e, estimula a ampla circulação do espaço da rua justamente pela dificuldade de manter-se em isolamento. As crianças e adolescentes permaneceram nas ruas, muitas vezes, para as atividades de socialização, mas também pela falta de espaço e de atividade dentro de casa.

Nesse tempo, a rua também se manteve como espaço de circulação dos trabalhadores, especialmente os trabalhadores informais. Tal situação gerou aglomerações nos transportes públicos e nas ruas, com a intensa exposição dos trabalhadores de aplicativos de entrega de comidas sob alegação de que a economia deveria se movimentar para evitar uma aguda crise 
econômica. No entanto, caminhamos há tempos em uma crise econômica e seu principal fator é a diminuição dos postos de trabalho, ou seja, a fragilização do trabalho formal que se reflete nas condições de vida de uma parcela da população.

Nesse quadro, o desemprego aumenta diariamente no país em descompasso às políticas emergenciais de contenção aos efeitos da pandemia junto à população desempregada, além das medidas governamentais não responderem às demandas dos trabalhadores desempregados com políticas de acesso ao emprego, dificultando ainda mais a inserção da massa de trabalhadores ao mercado de trabalho.

Desta forma, pode-se considerar que o quadro pandêmico revela mazelas sociais antigas do Brasil, a desigualdade se intensificou, mas as tensões sociais também se intensificaram. Escancarou-se diante de nós uma série de acontecimentos e práticas, sinalizando para o agravamento da questão social nesse periodo. Assim, o cuidado individual para lidar e enfrentar com a questão prevaleceu, enquanto as respostas de enfrentamento devem acontecer de forma coletiva com a realização de medidas propostas pelas diferentes esferas de governo.

Vale lembrar que a questão social remete para a estrutura de nossa sociedade e sua contradição, se expressa no conjunto das desigualdades sociais reveladas na vida social. Portanto, ela diz respeito também à condição de vida da população trabalhadora que ficou ainda mais vulnerável diante da atual pandemia. Tal condição explicitou a fratura constitutiva de nossa sociedade e a urgência das diferentes esferas de governo debaterem com o conjunto dos diferentes grupos sociais vulnerabilizados.

Neste contexto, se insere o debate sobre o direito à cidade, pois está diretamente associado às condições de vida da população e as possibilidades dos diferentes grupos presentes na sociedade poderem se utilizar dos bens comuns e dos serviços de utilidade pública disponíveis. Além disso, remete para a afirmação desses grupos nos espaços públicos constituidos nas diferentes cidades, sintetiza-se pelas possibilidades de ir e vir nas cidades com a garantia dos mínimos sociais para que se possa construir alternativas de existência e. resistência desses diferentes grupos nas cidades. 
A questão é desafiadora, e está associada à afirmação dos direitos e da realização de politicas sociais capazes de garantir ou promover diferentes formas de acesso aos grupos vulnerabilizados que ocupam, sobretudo, as grandes cidades brasileiras. Trata-se da afirmação e da ampliação da democracia em nossa sociedade.

Nesse esforço, o presente artigo propõe aproximar a reflexão entre o direito à cidade com a experiência vivida pelo moradores da comunidade de Paraisópolis, na cidade de São Paulo que se auto-organizaram para construirem alternativas à crise social e sanitária a qual foram expostos. Tal organização revela a insuficiência dos serviços e do poder público, mas revela também a força potencializadora de um movimento formado e articulado no território em questão.

Vale dizer que o texto se constitui como um exercício inicial de aproximação entre o conceito e o debate sobre o direito à cidade, bem como as experiências vivenciadas no território de Paraisópolis.

\section{SOBRE O DIREITO À CIDADE}

O direito à cidade é, de certa forma, um tema pouco evidente, mas é verdade que tem forte influência na vida de boa parte da população das diferentes cidades, especialmente as mais urbanizadas. Essas se definem pela lógica do capital, fator que se reflete de forma imediata na vida dos moradores das diferentes cidades.

É necessário sempre destacar que a cidade é mais do que um espaço social, mais do que construções e grandes edifícios, mais do que negócios e transações, pois corresponde também às experiências que os diferentes grupos de individuos vivenciam, sobretudo, de forma coletiva, seja por motivo de comemoração, seja por reivindicação quando há a ausência do seu direito ou a prevalência da lógica perversa do capital. Pode-se considerar que a cidade é o lugar, o espaço social onde seus individuos se constroem tanto individualmente quanto coletivamente. 
A questão em torno das diferentes formas de apropriação do espaço público das cidades, associada ao processo de expropriação e desigualdade social remete ao Direito à Cidade, noção debatida no século XX por $H$. Lefévre e retomada nos marcos da sociedade contemporânea, em tempos de prevalência do capital financeiro e do ajuste neoliberal, por D. Harvey. Nesta perspectiva, o direito à cidade refere-se ao debate e às possibilidades de utilização e reinvenção da cidade como espaço público que produz situações e experiências voltadas para o bem comum, permitindo os usos da cidade de forma coletiva, capaz, portanto, de se sobrepor aos acessos dos serviços disponíveis e a identificação das demandas individuais.

O direito à cidade é. portanto, muito mais do que um direito de acesso individual ou grupal aos recursos que a cidade incorpora: é um direito de mudar e reinventar a cidade mais de acordo com nossos mais profundos desejos. Além disso, é um direito mais coletivo do que individual, uma vez que reinventar a cidade depende inevitavelmente do exercicio de um poder coletivo sobre o processo de urbanização. A liberdade de fazer e refazer a nós mesmos e a nossas cidades [...] é um dos nossos direitos humanos mais preciosos, ainda que um dos mais menosprezados (HARVEY, 2014, p.28).

A urgência do direito à cidade pauta sobre o processo de urbanização das cidades e revela os processos de exclusão que marcaram a construção e apropriação dos espaços sociais, ou seja, historicamente a cidade se formou a partir das relações sociais instituidas com a consolidação do capitalismo, ou seja, a concentração de renda se revela nas formas de ocupação do espaço da cidade, promovendo a manutenção do processo de acumulação de lucros e de bens.

Reinventar o direito à cidade [...] equivale a reivindicar algum tipo de poder configurador sobre os processos de urbanização, sobre o modo como nossas cidades são feitas e refeitas, e pressupõe fazê-lo de maneira radical e fundamental. Desde que passaram a existir, as cidades surgiram da concentração geográfica e social de um excedente de produção. A urbanização sempre foi, portanto, algum tipo de fenômeno de classe, uma vez que os excedentes são extraídos de algum tipo de lugar ou de alguém, enquanto o controle sobre o uso desse lucro acumulado costuma permanecer nas mãos de poucos (HARVEY, 2014, p.30).

Portanto, viver nos grandes centros urbanos e, ao mesmo tempo, acessar as redes de serviços disponíveis neles pressupõe uma condição de vida ou de classe definida pelo poder de consumo, uma vez que os serviços são definidos como mercadorias e os modos de vida se apresentam como tendências de diferentes mercados promissores. Cabe ressaltar que os centros urbanos abarcam uma diversidade de produtos para o consumo referentes a qualidade 
de vida, cultura e aqueles que referem-se diretamente às condições básicas de sobrevivência, - que reforça o problema da desigualdade social.

A qualidade de vida urbana tornou-se uma mercadoria para os que têm dinheiro, como aconteceu com a própria cidade em um mundo no qual o consumismo, o turismo, as atividades culturais e baseadas no conhecimento, assim como o eterno recurso à economia do espetáculo, tornaram-se aspectos fundamentais da economia política urbana [...] A tendência pós-moderna a estimular a formação de nichos de mercado, tanto nas escolhas de estilo de vida urbano quanto hábitos de consumo e formas culturais, envolve a experiência urbana contemporânea em uma aura de liberdade de escolha no mercado, desde que você tenha dinheiro e possa se proteger da privatização da redistribuição da riqueza por meio da florescente atividade criminosa e das práticas fraudulentas e predatórias (HARVEY, 2014, p.46).

A questão sobre o destaque aos grandes centros urbanos diz respeito ao processo de acumulação da produção, bem como a concentração de riqueza, fatores que refletem na intensificação da pobreza nessas cidades e na construção de espaços privatizados que revelam diferentes formas de segregação da população em decorrência dos diferentes níveis de condição de vida da população.

Os resultados dessa crescente polarização na distribuição de riqueza e poder estão indelevelmente inscritos nas formas espaciais de nossas cidades, que cada vez mais se transformam em cidades de fragmentos fortificados, de comunidades muradas e de espaços públicos mantidos sob vigilância constante (HARVEY, 2014, p.48).

Se a segregação social se desenha nas diferentes formas de apropriação do espaço urbano, por outro lado, as lutas sociais daqueles que ficam de fora dos padrões de consumo da cidade se viabilizam. Desta forma, a organização de movimentos sociais urbanos e rurais reforçam sobre a urgência de incorporação de alternativas aos padrões de consumo vigente e à possibilidade de redesenhar os espaços das cidades, abarcando as demandas coletivas desses sujeitos sociais. As diferentes formas de luta e participação social são relevantes para que se denuncie os processos de exclusão e segregação das cidades, tanto quanto se esboce diferentes alternativas e modos de vida que não se definam pelo mercado de consumo, ao contrário que possam se definir como resultado da construção coletiva dos diferentes sujeitos sociais que ocupam o espaço urbano.

É de conhecimento geral que já está em andamento um grande diversificado número de lutas e movimentos sociais urbanos (no sentido mais amplo do termo, isto é, aquele que também inclui os movimentos nas zonas rurais). Em muitas partes do mundo, são abundantes as inovações urbanas acerca da sustentabilidade ambiental, da incorporação cultural dos imigrantes e do desenho urbano dos espaços habitacionais públicos. Contudo, elas ainda precisam se concentrar no objetivo único de adquirir maior controle sobre os usos do excedente (para não falar das condições em que se dá sua produção). Um passado rumo à unificação dessas lutas - ainda que de maneira alguma 
o último - consistiria em concentrar-se clara e inequivocadamente nesses momentos de destruição criativa nos quais a economia de acumulação de riquezas se transforme violentamente na economia de espoliação e ali proclame, em nome dos espoliados, seu direito à cidade - seu direito a mudar o mundo, a mudar a vida e a reinventar a cidade de acordo com seus mais profundos desejos. Esse direito coletivo, tanto como palavra de ordem quanto como ideal político, nos remete à antiquíssima questão de saber quem é que controla a conexão interna entre urbanização e produção e uso excedentes (HARVEY, 2014, p.65/66).

Apesar das diferenças sociais presentes e latentes na cidade, ao mesmo tempo, se realiza uma experiência e vivência comum que se constitui como um movimento que pode ser alterado quando se altera algo no espaço ou nas demandas dos diferentes grupos sociais. Segundo Harvey, a vida comum produz a "comunalidade", fruto da convivência de diferentes pessoas, de diferentes classes sociais.

A cidade é o lugar onde pessoas de todos os tipos e classes se misturam, ainda que relutante e conflituosamente, para produzir uma vida em comum, embora perpetuamente mutável e transitória. A comunalidade dessa vida tem sido há muito tempo objeto de análises de urbanistas de todas as tendências, além de tema frequente de uma vasta gama de textos e representações lem romances, filmes, pinturas, videos e outros meios afins) que tentam apreender o caráter dessa vida (ou o caráter particular da vida em uma cidade específica em um lugar e um tempo determinados) e o seu significado mais profundo (HARVEY, 2014, p.136).

A relevância desse debates, está no reconhecimento de que a experiência do comum pode ser capaz de alterar o curso da intensa financeirização e mercantilização que se instalaram nos diferentes tipos de produção e recursos que correspondem aos patrimônios comuns sejam eles históricos, geográficos, científicos ou culturais, configurando a função pública daquilo que é produzido e disponibilizado nos marcos da cidade.

Outros ainda (como o recurso hídrico comum controlado e compartilhado por cinquenta agricultores) são exclusivos de um grupo social específico desde o começo [...] Os comuns culturais são mercantilizados (e quase sempre atenuados) por uma indústria de turismo histórico que tende à disneyficação, por exemplo. Os direitos de propriedade intelectual e patentes sobre materiais genéticos e sobre o conhecimento científico em termos mais gerais constituem um dos temas mais polêmicos da nossa época (HARVEY, 2014, p.142).

Os espaços públicos formados nas cidades se definem pelas relações de poder e pelas regras da administração pública. Portanto, um bem público pode não se configurar como um bem comum. Tal fator revela a contradição da sociedade capitalista e o problema da luta de classes, sendo o próprio movimento e mobilização daqueles que não acessam os bens públicos que podem pressionar para a identificação das demandas comuns. Nesse sentido, a luta pelo direito à cidade configura-se em uma luta política. 
Há uma distinção importante entre os espaços públicos e bens públicos por um lado e. por outro, os comuns. Os espaços e os bens públicos urbanos sempre foram uma questão de poder de Estado e administração pública, e esses espaços e bens não constituem necessariamente um comum. Ao longo da história da urbanização, a provisão de espaços públicos e de bens públicos (como o saneamento, a saúde, a educação etc.) por meios públicos ou privados foi crucial para o desenvolvimento capitalista. Na medida em que as cidades têm sido espaços para vigorosos conflitos e luta de classes, a administração viu-se muitas vezes focada a suprir os bens públicos (como habitação de interesse social acessivel, sistema de saúde, educação, pavimentação das ruas, saneamento e águal a uma classe trabalhadora urbanizada. Embora esses espaços e bens públicos contribuam intensamente para as qualidades dos comuns, faz-se necessária uma ação política por parte dos cidadãos e das pessoas que pretendam apropriar-se deles ou concretizar essas qualidades [...] (HARVEY, 2014. p.143/ 144).

A luta pela consolidação do comum nas cidades e a luta pelo seu direito remete diretamente à luta contra o processo de acumulação que remete ao modo capitalista de produção, gerando a mercantilização dos bens públicos e dificultando a construção coletiva do espaço e dos bens comuns da cidade.

[...] o direito de usar esse comum deve ser concedido a todos aqueles que participaram de sua produção. Esta é certamente a base para a reivindicação do direito à cidade por parte dos trabalhadores coletivos responsáveis por sua criação. A luta pelo direito à cidade é contra os poderes do capital que se alimentam impiedosamente e extraem renda da vida comunal que outros produziram. Isso nos lembra que o problema real se encontra no caráter privado dos direitos de propriedade e do poder que eles conferem de apropriar não apenas o trabalho, como também as produções coletivas de outros. Em outras palavras, o problema não é comum per se mas as relações entre os que produzem e o conquistam pelo esforço em diferentes escalas e aqueles que dele se apropriam para seu benefício privado (HARVEY, 2014, p.153/154).

Nesse sentido, o direito à cidade abarca a reivindicação da coletividade de trabalhadores no enfrentamento ao processo de mercantilização, privatização e perpetuação das relações de poder instituidas. A luta pela coletividade é capaz de impulsionar o fortalecimento dos bens comuns no propósito de construir uma cidade mais justa, menos desigual e com oportunidades para os trabalhadores de forma indistinta de maneira a favorecer o desenvolvimento dos diferentes grupos sociais que fazem uso comum do espaço da cidade e constroem suas histórias também de forma coletiva.

\section{O TERRITÓRIO COMO ESPAÇO DE LUTA PELO DIRITO À CIDADE}

As medidas de combate a atual pandemia adotadas por organizações de moradores de Paraisópolis, uma das maiores favelas do país, localizada na região Sul da cidade de São Paulo, configuram-se como exemplo e esforço para a formação de espaços e bens comuns no 
respectivo território. A mobilização resulta da organização de lideranças sociais, moradores, comerciantes locais e doações de representantes da sociedade civil.

Cabe ressaltar que a favela vincula-se ao G10 favelas, uma organização de lideranças das maiores favelas do país. Contudo. Paraisópolis tem um prefeito local, eleito pela própria comunidade, o que revela a organização interna da comunidade, bem como seu esforço em pautar as próprias demandas, buscando respostas próprias para os efeitos do processo de desigualdade social e exclusão que um centro urbano como São Paulo impõe, em decorrência do fluxo do capital financeiro e do processo de produção material da vida social. $\bigcirc$ objetivo dos moradores parece ser construir uma comunidade com um nivel de qualidade de vida e com algum nível de desenvolvimento local. Portanto, há um esforço em construir um território com a presença de bens comuns aos seus moradores, capaz de se constituir como uma alternativa aos efeitos perversos da lógica do capital financeiro. Nesse sentido, o exemplo de Paraisópolis é emblemático, é verdade que não é único, temos nos grandes centros urbanos a formação de coletivos para pautar suas demandas sejam sociais, culturais e econômicas, apresentando, assim, alternativas anticapitalistas para que seja possivel construir uma cidade acessível a todos e possibilidades de resistência, ou mesmo, de sobrevivência nos centros do capital financeiro.

O exemplo de Paraisópolis tem sido destaque da grande mídia e da mídia alternativa justamente pela capacidade que a comunidade teve em mobilizar recursos e esforços para cuidar da população, propondo medidas de contenção à propagação do vírus, promovendo alternativas para a garantia do isolamento social, bem como geração de renda de uma parcela de seus moradores.

No ápice do isolamento social, a comunidade conseguiu se organizar e contratar profissionais de saúde, uma vez que seus moradores têm dificuldades em acessar a rede de serviços públicos; escolas foram utilizadas como espaço para realização de isolamento de moradores em vulnerabilidade para evitar a propagação do vírus. A ação organizada contou com a gestão de um comitê de crise, com o trabalho de lideranças como presidentes de ruas ou de quadras para acompanhar a situação das famílias, com parte dos recursos foi possível produzir internamente refeições para serem revertidas às familias que perderam suas rendas. entre outras ações locais. 
Tal quadro nos revela a força potencializadora da mobilização e ação de movimentos da sociedade em apresentar alternativas à ausência da ação do poder público e de enfrentamento às demandas causadas pela contradição do capital.

Desta forma, o território revela suas particularidades, vulnerabilidades e, especialmente as demandas coletivas do grupo que pertence a ele. Pode-se justamente pensar que o território é o espaço das experiências vividas, da prática cotidiana das pessoas que residem no local, mas que desenvolve um sentimento de pertencimento a esse espaço, identificandose com ele e com as pessoas que também residem nele (KOGA, 2003).

Vale destacar que a abordagem territorial tem sido princípio de politicas para que se pense respostas às demandas efetivas e coletivas de parcelas em situação de vulnerabilidade ou risco social, mas diante do destaque da mobilização dos moradores de Paraisópolis, cabe a reflexão sobre o quanto efetivamente o poder público consegue estar intensamente presente em um território como Paraisópolis.

Segundo Raichelis (2006 apud COUTO; YAZBEK; SILVA e SILVA; RAICHELIS, 2017, p.81), o território "expressa a emergência de um novo padrão de organização das diferenças no espaço urbano", permitindo a redefinição dos "processos de interação social e de sociabilidade coletiva, promove acessos diferenciados à informação, à diversidade de oportunidades e aos equipamentos e bens públicos, transformando as concepções de público e os parâmetros de convivência".

Como ressalta Koga (2003, p.39), a "dimensão territorial traz elementos que permitem uma perspectiva de totalidade da questão social: refere às próprias relações estabelecidas entre os sujeitos e seu cotidiano de vivência". Tal relação se apresenta como contrária à "corriqueira e simplista noção de necessitados ou carentes como comumente se referem as políticas direcionadas aos pobres, que se destitui da condição do sujeito".

A ação potencializadora e protagonista dos moradores de Paraisópolis é relevante, pois remete à auto-organização desse grupo, indicando que há caminhos possiveis para enfrentar os efeitos da atual crise sanitária, mas também aos problemas enfrentados por eles que remetem ao conjunto das expressões da questão social. 
Nesse processo, a ação desenvolvida no território de Paraisópolis se configura na perspectiva de desenvolver uma sociabilidade coletiva ou como afirma Harvey, desenvolver usos e bens comuns no espaço urbano denotando a noção de comunalidade, uma vez que ao se organizarem, revelaram suas demandas e esboçaram possibilidades dentro do próprio território, bem como as repostas de enfrentamento aos reflexos da desigualdade social que determina a condição dos moradores da comunidade.

No entanto, as respostas possiveis às demandas são postas em prática no processo da associação de moradores buscarem espaço para sinalizarem suas demandas, ao mesmo tempo, em que sinalizam ao poder público sua ausência e a possibilidade desse pensar uma agenda governamental para o investimento na construção de bens comuns na grande cidade que é São Paulo. Outro aspecto que merece atenção é a visibilidade que a auto-organização de Paraisópolis ganha, sendo capaz de mostrar para a cidade e o país o protagonismo e a existência de seus moradores.

Nesse quadro, a circulação dos moradores para outros territórios da cidade de São Paulo pode ser reforçada, uma vez que todas essas iniciativas e visibilidade podem ajudar a reforçar a identidade desses moradores dentro da própria cidade, ampliando a rede de vínculos e a utilização dos espaços, ampliando também a possibilidade do encontro de lutas sociais comuns no espaço urbano que é São Paulo.

Tal movimento pode favorecer a luta por uma cidade mais solidária, mais justa e menos desigual, chamando a atenção para a urgência da efetivação do direito à cidade para todos os grupos ou sujeitos sociais que residem nela, chamando a atenção para o debate sobre a privatização de bens públicos, fortalecendo as lutas sociais e a construção de alternativas que se constituam como ações de resistência ao movimento do capital e favoreçam a circulação dos cidadãos no espaço urbano de forma a ampliar os limites dos diferentes territórios, mesclando diferentes comunalidades e experiências vividas e vivenciadas por diferentes sujeitos sociais.

O que está em questão é a construção de um espaço urbano humanizado e menos excludente, construindo alternativas possiveis para diferentes formas de sobrevivência e resistência, promovendo o encontro e o diálogo entre diferentes grupos que residem na cidade, vislumbrando o rompimento entre muros e o processo de exclusão social. 


\section{REFERÊNCIAS BIBLIOGRÁFICAS}

AUGÉ, M. Não lugares: Introdução a uma antropologia da supermodernidade. Campinas: Papirus, 2012.

COUTO, B.: YAZBEK, C.: SILVA e SILVA, M.: RAICHELIS, R. (orgs.) O Sistema Único de Assistência Social no Brasil. São Paulo: Cortez, 2017.

DOWBOR, L. A Era do Capital Improdutivo. São Paulo: Autonomia Literária, 2017.

FILHO, N.A, AZEVEDO, G., TRAVASSOS, C. 2020. Como controlar a pandemia no Brasil. Le Monde Diplomatique. 157,8-9.

GRABOIS, A.P. 2020. A voz ativa contra a Covid-19 no Complexo do Alemão, ignorado pelo governo na pandemia. El Pais. Disponivel em: https://brasil.elpais.com/brasil/2020-08-16/a-vozativa-contra-a-covid-19-no-complexo-do-alemao-ignorado-pelo-governo-na-pandemia.html Acesso em Agosto/2020

HARVEY, David. Condição Pós-moderna. São Paulo: edições Loyola, 1992.

Fontes, 2014. Cidades Rebeldes: do direito à cidade à revolução urbana. São Paulo: Martins A Loucura da Razão Econômica. São Paulo: Boitempo, 2018.

IAMAMOTO, M.V. 2001. A questão social no capitalismo. Temporalis. Ano II, 3, 9-32.

INESC. 2020. Bolsonaro, a pandemia e a explosão das demandas sociais. Le Monde Diplomatique. №157.

KOGA. D. Medidas de Cidades: entre territórios de vida e territórios vividos. São Paulo: Cortez, 2003.

LIMA, J.D. 2020. Por que Paraisópolis se destaca no combate ao Coronavírus. Nexo Jornal. Disponivel em: https://www.nexojornal.com.br/expresso/2020/07/01/Por-queParais $\%$ C 3\%B3polis-se-destaca-no-combate-ao-coronav $\%$ C $3 \%$ ADrus Acesso em Agosto/2020.

MARICATO, Ermínia [et.al.]. Cidades Rebeldes: Passe Livre e as manifestações que tomaram as ruas do Brasil. São Paulo: Boitempo/ Carta Maior, 2013. 